\title{
Quantifying Relationships Among Phosphorus, Agriculture, and Lake Depth at an Inter-Regional Scale
}

\author{
Zofia E. Taranu* and Irene Gregory-Eaves
}

Department of Biology, McGill University, 1205 Docteur Penfield, Montreal, Quebec, Canada H3A 1B1

\begin{abstract}
To date, studies examining the impact of agriculture on freshwater systems have been spatially confined (that is, single drainage basin or regional level). Across regions, there are considerable differences in a number of factors, including geology, catchment morphometry, and hydrology that affect water quality. Given this heterogeneity, it is unknown whether agricultural activities have a pervasive impact on lake trophic state across large spatial scales. To address this issue, we tested whether the proportion of agricultural land in a catchment (\% Agr) could explain a significant portion of the variation in lake water quality at a broad inter-regional scale. As shallow, productive systems have been shown to be particularly susceptible to eutrophication, we further investigated how lake mean depth modulates the relationship between \% Agr and lake total phosphorus (TP) concentration. We applied both traditional metaanalytic techniques and more sophisticated linear mixed-effects models to a dataset of 358 temperate
\end{abstract}

\section{INTRODUCTION}

Eutrophication of surface waters remains a persistent and extensive problem, and is one of the primary threats to global water quality (UNEP 2007). It often results in biodiversity losses, reduced recreation potential, and diminished ecosystem services (for example, loss of potable water) causing

Received 31 July 2007; accepted 25 April 2008; published online 22 May 2008

*Corresponding author; e-mail: zofia.taranu@mail.mcgill.ca lakes that spanned an extensive spatial gradient $\left(5^{\circ} \mathrm{E}\right.$ to $\left.73^{\circ} \mathrm{W}\right)$ to address these issues. With metaanalytical techniques we detected an across-study correlation between TP and \% Agr of 0.53 (onetailed $P$-value $=0.021)$. The across-study correlation coefficient between TP and mean depth was substantially lower $(r=-0.38 ; P=0.057)$. With linear mixed-effects modeling, we detected amongstudy variability, which arises from differences in pre-impact (background) lake trophic state and in the relationship between lake mean depth and lake TP. To our knowledge, this is the first quantitative synthesis that defines the influence of agriculture on lake water quality at such a broad spatial scale. Syntheses such as these are required to define the global relationship between agricultural land-use and water quality.

Key words: agriculture; non-point source; water quality; phosphorus; eutrophication; morphometry; meta-analysis; mixed-effects model.

both ecological and economic hardship for surrounding communities (Pretty and others 2003). Understanding and managing the causes of eutrophication has been a primary goal of limnological research over approximately the past 40 years (for example, Vollenweider 1968; Dillon and Rigler 1974; Schindler 1974; Downing and McCauley 1992).

Human activity has led to the nutrient enrichment of many freshwater systems around the world (Smith and others 1999). Point-source loading (for 
example, from sewage effluent) was first recognized as an important cause of lake eutrophication. Mitigation of these sources has not always successfully reduced surface water nutrient concentrations and algal growth, however, as diffuse nutrient inputs (for example, agricultural run-off) are often substantial (Hamm 1976; Ryding 1981; Kronvang and others 1993, 2005). In the second half of the 20th century, researchers noted that although progress had been made in curbing point sources of nutrient loading to surface water in many parts of the world, non-point contributions remained a widespread and often overlooked cause of eutrophication (Carpenter and others 1998).

Establishing the impact of agricultural runoff on the quality of limnetic systems is crucial as nearly $24 \%$ of the world's land area is currently subjected to some form of agricultural management (Millennium Ecosystem Assessment 2005). With exponential human population growth, increasing consumer demand, and an increase in agricultural land cover averaging $2.2 \%$ per year, there is little indication of a future decrease or stabilization in agricultural production (FAOSTAT 2007). If these trends persist, it is predicted that approximately 1 billion hectares of land will be converted to agriculture within the next 40 years (Tilman and others 2001). If a significant global relationship between water quality and agricultural land does in fact exist, this predicted increase in agricultural practices will have important repercussions on the quality of inland water bodies worldwide.

Nearly a decade has passed since Carpenter and others' (1998) review paper was published, stressing the importance of diffuse loading on water quality. This article was a culmination of many years of work in the field and acknowledged a focal shift in interest from point-source effects to those of diffuse nutrient loading. Since this publication, the scientific community has continued to demonstrate a growing interest in issues relating to effects of diffuse loading and eutrophication. For example, by conducting a literature search based on the five journals with the greatest number of hits in the ISI Web of Science for the keywords 'agriculture' and 'water quality', we noted a significant increase in the proportion of articles published each year between 1990 and $2006(r=0.86 ; P<0.001)$. Interestingly, over $93 \%$ of the studies identified were conducted at a local or regional scale (that is, at the lake/catchment or landscape scale). Whereas these studies have advanced our understanding of the effects of diffuse nutrient loading to inland waterbodies and enable us to make local-scale predictions, their quantitative synthesis will ulti- mately provide a general model to assess the ubiquity of the impact of agriculture across numerous regions. Such syntheses are critical as we know that across regions there are numerous factors that can influence lake-water total phosphorus (TP), including precipitation (Chang and others 1992; Soranno and others 1996), catchment morphometry (Prairie and Kalff 1986; D'Arcy and Carignan 1997; Ekholm and others 2000), soil topology (Bennett and others 2001), and geology (Dillon and Kirchner 1975). Hence, it is not obvious from localized studies what the effect of agriculture is at a larger, inter-regional scale. Furthermore, by addressing the variability of the impact of non-point loading on water quality among regions, we can better appreciate in which parts of the world are lakes most susceptible to eutrophication as a result of agricultural land use.

The primary objective of this study is to test the hypothesis that the percent of agriculture in a lake's catchment (\% Agr) explains a significant fraction of the variation in lake surface water TP concentrations across studies. Because heterogeneity in environmental conditions and background TP levels may exist at such broad spatial scales, running a simple linear regression between \% Agr and TP for all sites across studies is not an appropriate approach. This technique would not have taken into account differences in baseline TP across regions. Instead, we applied meta-analytical and mixed-effects modeling techniques to synthesize the overall across-study effect of agriculture on water quality based on study-specific correlations, and to address the among-study variability, respectively.

We have also examined the effect of lake mean depth given that early work by Vollenweider (1968) recognized lake mean depth, a synthetic variable for lake morphometry and water residence time, as an important predictor of TP. Furthermore, shallow lakes, by nature of their morphometry, are more prone to the recycling of phosphorus from their bottom sediments to surface waters (Kalff 2001). Thus, we have defined what proportion of the variability in TP that can be explained by lake mean depth $\left(Z_{\text {mean }}\right)$ and \% Agr in a lake's catchment.

\section{MethodS}

\section{Meta-Analyses}

To quantify the impact of diffuse agricultural nutrient loading on the quality of inland lakes at an inter-regional scale (Figure 1), we conducted a meta-analysis. Based on a review of the literature, we identified nine studies reporting the average 

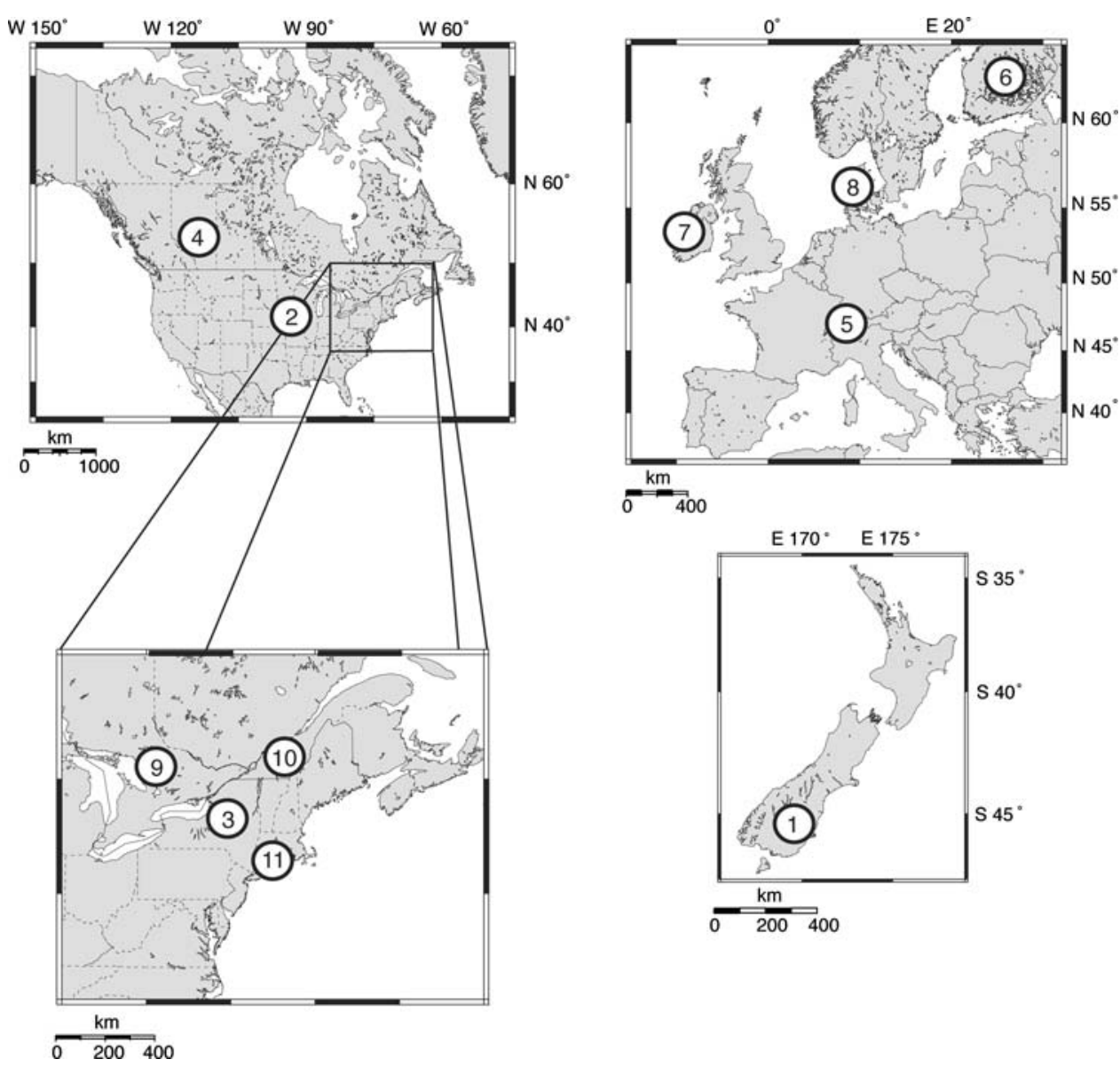

Figure 1. Map of studies used in meta-analysis and mixed-effects modeling: (1) Otago, New Zealand (Galbraith and Burns 2007); (2) Iowa (Mississippi River Basin), USA (Arbuckle and Downing 2001); (3) Northeastern USA (Whittier and others 2002); (4) Eastern and Central Alberta, Canada (Taranu and Gregory-Eaves, this study); (5) Switzerland (Müller and others 1998); (6) Southern and Central Finland (Ekholm and Mitikka 2006); (7) Ireland (Chen and others 2008); (8) Central and Northern Jutland, Denmark (Vander Zanden and others 2005); (9) Central and Eastern Ontario, Canada (Paterson and others 2006); (10) Southeastern Québec, Canada (Prairie and Parkes unpublished); and (11) Connecticut, USA (Norvell and others 1979). Study regions were numbered according to the strength of their correlation coefficient between TP and \% Agr (see Table 1).

summer TP within lakes and \% Agr. Three additional datasets, currently unpublished or in press, were also included in our analysis. One of the 12 studies, however, had a very small dataset (Smal and others 2005; sample size $=5$ ) and thus was not included in further analyses. We conducted our analyses on average summer TP data, which for each lake represents the mean TP across the open water season (that is, values averaged between April and November for all studies with the exception of the New Zealand dataset where samples were collected during the austral summer). TP was used as a proxy for water quality because it has been shown to be a strong predictor of algal growth (chlorophyll a) across a range of total nitrogen: total phosphorus ratios (Prairie and others 1989). For each study, the \% Agr variable represents the per- centage of catchment land under pastoral grazing and row cropping (not all studies, however, distinguished different categories of agriculture). From our literature review, we noted that \% Agr was reported more often than total area of agricultural land ( Agr $_{\text {area }}$ ). To assess whether \% Agr was a more appropriate metric of diffuse agricultural nutrient loading, we conducted a comparative analysis of the strength of the relationship between TP-\% Agr to that of TP-Agrarea. Lake mean depth data were available for ten of these studies, which allowed us to test the influence of $Z_{\text {mean }}$ as well as \% Agr on TP.

The focus of our article is on diffuse nutrient loading. Thus, to minimize the influence of pointsource nutrient loading, we eliminated sites with greater than $10 \%$ urban land cover in the 
Table 1. TP-\% Agr and TP- $Z_{\text {mean }}$ Correlation Coefficients, Study Sample Sizes, and Correlation $P$-Values

\begin{tabular}{|c|c|c|c|c|c|c|}
\hline \multirow[t]{2}{*}{ Study } & \multicolumn{3}{|c|}{$\begin{array}{l}\text { Correlation between \% } \\
\text { Agr and TP }\end{array}$} & \multicolumn{3}{|c|}{$\begin{array}{l}\text { Correlation between } Z_{\text {mean }} \\
\text { and TP }\end{array}$} \\
\hline & $r$ & $n$ & $P$-value & $r$ & $n$ & $P$-value \\
\hline (1) Galbraith and Burns (2007) & 0.15 & 24 & 0.233 & - & - & - \\
\hline (2) Arbuckle and Downing (2001) & 0.37 & 30 & 0.022 & -0.47 & 30 & 0.005 \\
\hline (3) Whittier and others (2002) & 0.40 & 25 & 0.023 & -0.38 & 25 & 0.031 \\
\hline (4) Taranu and Gregory-Eaves (this study) & 0.43 & 36 & 0.005 & -0.56 & 33 & 0.0003 \\
\hline (5) Müller and others (1998) & 0.47 & 55 & 0.0002 & -0.18 & 55 & 0.099 \\
\hline (6) Ekholm and Mitikka (2006) & 0.50 & 18 & 0.017 & -0.68 & 13 & 0.005 \\
\hline (7) Chen and others (2008) & 0.56 & 75 & $<0.0001$ & -0.16 & 75 & 0.082 \\
\hline (8) Vander Zanden and others (2005) & 0.58 & 22 & 0.002 & -0.41 & 22 & 0.030 \\
\hline (9) Paterson and others (2006) & 0.65 & 35 & $<0.0001$ & -0.66 & 35 & $<0.0001$ \\
\hline (10) Prairie and Parkes (unpublished) & 0.73 & 20 & 0.0001 & -0.80 & 15 & $<0.0001$ \\
\hline (11) Norvell and others (1979) & 0.86 & 18 & $<0.0001$ & 0.13 & 18 & 0.310 \\
\hline
\end{tabular}

$r=$ correlation coefficient and $n=$ sample size, $T P=$ summer average total phosphorus concentrations ( $\mu$ g/l) of surface waters, \% Agr $=$ percent of agricultural land cover in the lake catchment, and $Z_{\text {mean }}=$ lake mean depth in meters.

catchment. The land-cover data were not sufficiently detailed to determine whether urban land cover was greater than $10 \%$ in only two datasets. In these cases, however, the authors reported qualitatively in their article that the urban land cover was negligible (Arbuckle and Downing 2001; Prairie and Parkes unpublished). Once the datasets were screened for possible point-source nutrient loading, natural log or square-root data transformations were applied to the necessary study lake sets to normalize the distributions. All $Z_{\text {mean }}$ values were $\log$ transformed to obtain approximate normal distributions. For the LMMs, however, common natural log transformations were applied across all study sets as the entire dataset is analyzed at once when using this statistical method.

For two datasets, one from Northeastern USA and the other from Midwestern USA (Arbuckle and Downing 2001; Whittier and others 2002), we found that the \% Agr and TP data had skewed distributions and could not be corrected with log or square-root transformations. In the Northeastern USA dataset (with $>10 \%$ urban sites removed), \% Agr varied between $0 \%$ and $90 \%$, but 217 out of 317 lakes had $1 \%$ or less Agr in their catchments (Whittier and others 2002). To obtain a more even distribution, we randomly sub-sampled lakes from this dataset following a block design (that is, randomly selecting an equal number of lakes within intervals of $15 \%$ Agr increments). Likewise, the \% Agr distribution of the Midwestern USA study was strongly skewed with a median of $91 \%$ Agr. In a similar random sub-sampling procedure, six lakes from equal-sized \% Agr intervals were kept for our meta-analyses and mixed-effects models (Arbuckle and Downing 2001). Bootstrap resampling with replacement (1000 simulations) demonstrated that the randomly chosen subsets did not influence our results. All analyses described below are based on these modified datasets.

The meta-analysis of this large dataset enabled us to not only determine the presence of an effect, but also to quantify its magnitude, known as the across-study effect size (Rosenberg and others $2000)$. The effect size for each study $(k)$ was calculated with the use of the Fisher's $Z$-transformation $\left(Z_{k}\right.$; equation 1$)$, where $r$ corresponds to the within-study correlation coefficient obtained when TP is correlated to either \% Agr, Agr $_{\text {area }}$ or $Z_{\text {mean }}$. The variance for each study ( $V_{k}$; equation 2 ) is inversely proportional to the study sample size $(n)$. To calculate both the effect size and variance for each study, we used the MetaWin software (Rosenberg and others 2000) to apply the following formulae:

$$
\begin{gathered}
Z_{k}=\frac{1}{2} \ln \left\{\frac{(1+r)}{(1-r)}\right\} \\
V_{k}=\frac{1}{(n-3)}
\end{gathered}
$$

The overall across-study effect size $(\hat{E})$ is calculated by summing the individual study effect sizes $\left(Z_{k}\right)$, weighted by their variance $\left(V_{k}\right.$; equation 3$)$.

$$
\hat{E}=\frac{\sum_{k} w_{k} Z_{k}}{\sum_{k} w_{k}}
$$

where $w_{k}=1 / V_{k}$. Using these formulae, we summarized the overall relationship between agriculture 
( $\%$ Agr and Agr $\left._{\text {area }}\right)$, mean lake depth $\left(Z_{\text {mean }}\right)$, and water quality (TP).

\section{Linear Mixed-Effects Models}

Although meta-analyses determine the strength of inter-regional correlative relationships, information on data distributions and within-study regression parameters is inevitably lost. Furthermore, as it is not possible to calculate a correlation coefficient among three variables (that is, $Z_{\text {mean }}$ as a second covariate in addition to \% Agr), we could not conduct a metaanalysis of the multiple TP, \% Agr, and $Z_{\text {mean }}$ relationship. To further advance our understanding of the among-study variability, we applied linear mixed-effects modeling (LMM) to test whether the slopes and intercepts of the relationship between \% Agr, $Z_{\text {mean, }}$ and TP differed across studies. These analyses were conducted using the $R$ statistical software (R Development Core Team 2007) and package "Ime4" provided by Bates (2005).

LMMs often provide improvements over ordinary least squares (OLS) regressions because the former include within-study model parameters that control for structure at the study level. More specifically, LMMs account for variability due to among-study differences in the dataset. In contrast, OLS simply incorporates this structure into the residual variance, which can lead to an inflation of the within-study variability estimate. LMMs contain both common (that is, fixed) and flexible (that is, random) terms, where the common effects are the across-study parameters and the flexible effects are the within-study parameters (Pinheiro and Bates 2004). An example of an LMM with a common predictor variable (that is, same slope across all studies) and a flexible intercept term (that is, varies among studies) is given by the equation

$$
Y_{j k}=X_{j k} \beta+\mathrm{U}_{\mathrm{k}}+\mathrm{E}_{\mathrm{jk}}
$$

where the indices $j$ and $k$ represent the lake and study number, respectively, $\beta$ is the common across-study regression slope, and $U_{k}$ is a flexible variable assigned to study $k$. Thus each study is allocated a different intercept value. If a metadataset has structure at the study level, model (4) will have a smaller error variance than the OLS model (5) that does not allow for variance of intercepts.

$$
Y_{j k}=X_{j k} \beta+\mathrm{E}_{\mathrm{jk}}
$$

The simplest model examined with our metadataset (where $j=1$ to 358 ) is the OLS regression for which TP is estimated by the mean TP value across all studies (that is, estimating the common across study intercept, which is the expected value, $E\left[Y_{j k}\right]$, of TP) (equation 6; Table 2).

Our first LMM assessed the variability of intercept coefficients among studies by introducing a flexible term $U_{0 k}$, which allowed for variation in mean $Y_{j k}$ (equation 7; Table 2). As we were interested in the degree to which the percent of agriculture in the catchment explained the variance in limnetic TP, we further added a common predictor variable ( $\%$ $\left.\operatorname{Agr}_{j k}\right)$, corresponding to \% Agr, to examine the reduction in residual variance when a common slope $\left(\beta_{1}\right)$ was included in the model in addition to the flexible intercept term $\left(U_{0 k}\right)$ (equation 8; Table 2). Finally, to assess whether the \% Agr slope coefficients varied considerably among studies, we examined the change in residual variance when, in addition to a flexible intercept $\left(U_{0 k}\right)$ and a common slope $\left(\beta_{1}\right)$, we included a flexible study slope parameter for \% Agr $\left(U_{1 k}\right)$ (equation 9; Table 2).

Because the response of lakes to external loading is often dependent on lake depth (Borsuk and others 2001), we included mean lake depth as an additional independent variable in a second set of LMMs. This allowed us to test whether there was

\begin{tabular}{|c|c|c|c|c|c|c|c|c|c|c|}
\hline Model & Equation & $\beta_{0}$ & $\tau_{0 k}$ & $\beta_{1}$ & $\tau_{1 k}$ & $\beta_{2}$ & $\tau_{2 k}$ & $\sigma$ & AIC & $\mathrm{BIC}$ \\
\hline 6 & $Y_{j}=\beta_{0}+\mathrm{E}_{\mathrm{j}}$ & 3.25 & - & - & - & - & - & 1.00 & 936 & 944 \\
\hline 7 & $Y_{j k}=\beta_{0}+\mathrm{U}_{0 \mathrm{k}}+\mathrm{E}_{\mathrm{jk}}$ & 3.33 & 0.72 & - & - & - & - & 0.75 & 848 & 856 \\
\hline 8 & $Y_{j k}=\beta_{0}+\% \mathrm{Agr}_{\mathrm{jk}} \beta_{1}+\mathrm{U}_{0 \mathrm{k}}+\mathrm{E}_{\mathrm{jk}}$ & 2.63 & 0.61 & 0.25 & - & - & - & 0.67 & 772 & 783 \\
\hline 9 & $Y_{j k}=\beta_{0}+\% \operatorname{Agr}_{j \mathrm{k}} \beta_{1}+\% \operatorname{Agr}_{\mathrm{jk}} \mathrm{U}_{1 \mathrm{k}}+\mathrm{U}_{0 \mathrm{k}}+\mathrm{E}_{\mathrm{jk}}$ & 2.66 & 0.68 & 0.25 & 0.08 & - & - & 0.66 & 774 & 793 \\
\hline 10 & $Y_{j k}=\beta_{0}+\% \mathrm{Agr}_{\mathrm{jk}} \beta_{1}+\mathrm{Z}_{\mathrm{mean}, \mathrm{jk}} \beta_{2}+\mathrm{U}_{0 \mathrm{k}}+\mathrm{E}_{\mathrm{jk}}$ & 3.18 & 0.60 & 0.26 & - & -0.36 & - & 0.64 & 669 & 684 \\
\hline 11 & $Y_{j k}=\beta_{0}+\% \operatorname{Agr}_{j \mathrm{k}} \beta_{1}+Z_{\text {mean }, \mathrm{k}} \beta_{2}+Z_{\text {mean }, \mathrm{k}} \mathrm{U}_{2 \mathrm{k}}+\mathrm{U}_{0 \mathrm{k}}+\mathrm{E}_{\mathrm{jk}}$ & 3.27 & 0.86 & 0.26 & - & -0.44 & 0.21 & 0.63 & 665 & 687 \\
\hline
\end{tabular}

Table 2. Mixed-Effects Model Equations and Results 
variability in the relationship between $\mathrm{TP}$ and $Z_{\text {mean }}$ among studies. Here we investigated whether the common slope for $Z_{\text {mean }}\left(\beta_{2}\right)$ resulted in a significant model improvement relative to the model with a common across-study \% Agr slope $\left(\beta_{1}\right)$ and a flexible intercept term $\left(U_{0 k}\right)$ (that is, comparing equations 8 and 10; Table 2).

To assess the interplay between lake depth and water quality among study regions, we examined whether the $Z_{\text {mean }}$ slope $\left(\beta_{2}\right)$ varied among studies by introducing a flexible study slope parameter for $Z_{\text {mean }}\left(U_{2 k}\right)$. Therefore, we asked whether the individual study slopes associated with $Z_{\text {mean }}$ had a quantifiable variance (equation 11; Table 2).

To define which of the above models was the "best model" (Kass and Raftery 1995), we used parsimonious model selection criteria, namely the Akaike's Information Criterion (AIC) and the Bayesian Information Criterion (BIC). Both criteria are based on a compromise between model fit and complexity, where the fit always increases as more parameters are added; however, the addition of too many parameters (that is, increased complexity) results in non-generalizable models (Johnson and Omland 2004). The lowest AIC provides us with an indication of which model is the best asymptotic approximation to the true model, but tends to overestimate the number of required model parameters. The lowest BIC, in contrast, highlights the model with the highest probability of being correct but penalizes more severely models with a large number of parameters.

\section{RESUlts}

Variation in Water Quality, Agriculture, and Lake Depth Across Studies

We incorporated data from 11 studies (covering a total of 358 lakes), which spanned extensive ranges in TP $(0-897 \mu \mathrm{g} / \mathrm{l}$; median $=22 \mu \mathrm{g} / \mathrm{l}), \%$ Agr $(0-100 \%$; median $=29 \%)$, Agr area $\left(0-101700 \mathrm{~km}^{2}\right.$; median $\left.=2.5 \mathrm{~km}^{2}\right)$, and $Z_{\text {mean }}(0.7-28.2 \mathrm{~m}$; median $=4.6 \mathrm{~m}$ ) in our analyses. As several studies provided more information on the type of agriculture, we know that at least a few regions were dominated by pastureland (namely Galbraith and Burns 2007; Chen and others 2008; Prairie and Parkes unpublished), whereas others were predominantly cropland (namely Arbuckle and Downing 2001; Vander Zanden and others 2005; Ekholm and Mitikka 2006). Given this variability in agricultural land-use practices and in the data ranges represented across studies, we, not surprisingly, found a broad spectrum of correlation coefficients $(r=0.15-0.86)$ when the TP-\% Agr relationship was assessed with linear correlation for each study individually (Table 1).

\section{Meta-Analyses}

In our first meta-analysis, we examined the general TP-\% Agr relationship, for which we observed an across-study correlation coefficient of 0.53 (onetailed $P$-value $=0.021)$. The effect size of the TPAgr $_{\text {area }}$ relationship was considerably weaker and non-significant $(r=0.38, P=0.059)$. This finding is supported by the work of Prairie and Kalff (1986), who demonstrated that the TP exported per unit catchment area decreases as the area of the catchment increases. We therefore disregarded Agr $_{\text {area }}$ from further analyses.

In comparing the effect size of the TP-\% Agr relationship to that calculated for the TP- $Z_{\text {mean }}$ relationship ( $r=-0.38, P=0.057)$, we note that the former is substantially stronger. This observation may initially seem unusual because the strength of correlation coefficients for both the TP-\% Agr and TP- $Z_{\text {mean }}$ relationships were similar (Table 1). The latter, however, had a bimodal frequency distribution of correlation coefficients (that is, higher occurrence of small $r$-values; Table 1). As such, lake mean depth was a good predictor of TP in some regions, but performed poorly in other parts of the world. We suggest that the high degree of variability in the TP- $Z_{\text {mean }}$ relationship across regions may have led to a relatively weak inter-regional model. The TP- $Z_{\text {mean }}$ and TP-\% Agr relationships further differed in that the individual slope and correlation coefficients of the former relationship were negative, whereas those of the latter relationship were positive. Finally, we are confident that our two independent variables, \% Agr and $Z_{\text {mean }}$ explain a separate amount of the variation in TP as we failed to detect multicollinearity between these two variables (that is, a meta-analysis of the correlation between \% Agr and $Z_{\text {mean }}$ demonstrated a non-significant across-study correlation coefficient; $r=0.12$, two-tailed $P$-value $=0.34$ ).

\section{Mixed Effects Models: Variability in the Correlative Relationship Between TP and \% Agr}

By comparing the OLS regression model results (equation 6) to those of an LMM with a flexible intercept term (equation 7), we noted that both the AIC and BIC decreased when the variability due to study structure was specifically incorporated into the model (equation 7), instead of being lumped 
into the random error term (equation 6). Thus, the LMM with a flexible intercept term for each study (equation 7) significantly improved TP predictions relative to the OLS model (likelihood ratio test $=$ 188.3; $P<0.001)$ and led to a decrease in the residual standard deviation (Table 2 ).

The second mixed-effect model examined, allowing for a flexible intercept term and a common \% Agr slope (equation 8), demonstrated a significant across-study common slope $\left(\beta_{1}=0.25\right.$; $P<0.001)$ as well as a decrease in the flexible intercept $\left(U_{0 k}\right)$ and model error $\left(E_{j k}\right)$ variances. This implies that each individual study has the same slope coefficients (that is, comparable increases in TP per unit increase in \% Agr), but different intercept coefficients (that is, regional variability in the pre-impact TP concentrations). The LMM predicted values are thus a compromise between the predicted values obtained when running separate OLS analyses for each study and those obtained when running a single OLS analysis for the entire dataset (Figure 2). The mixed-effects estimates are often referred to as shrinkage estimates as they

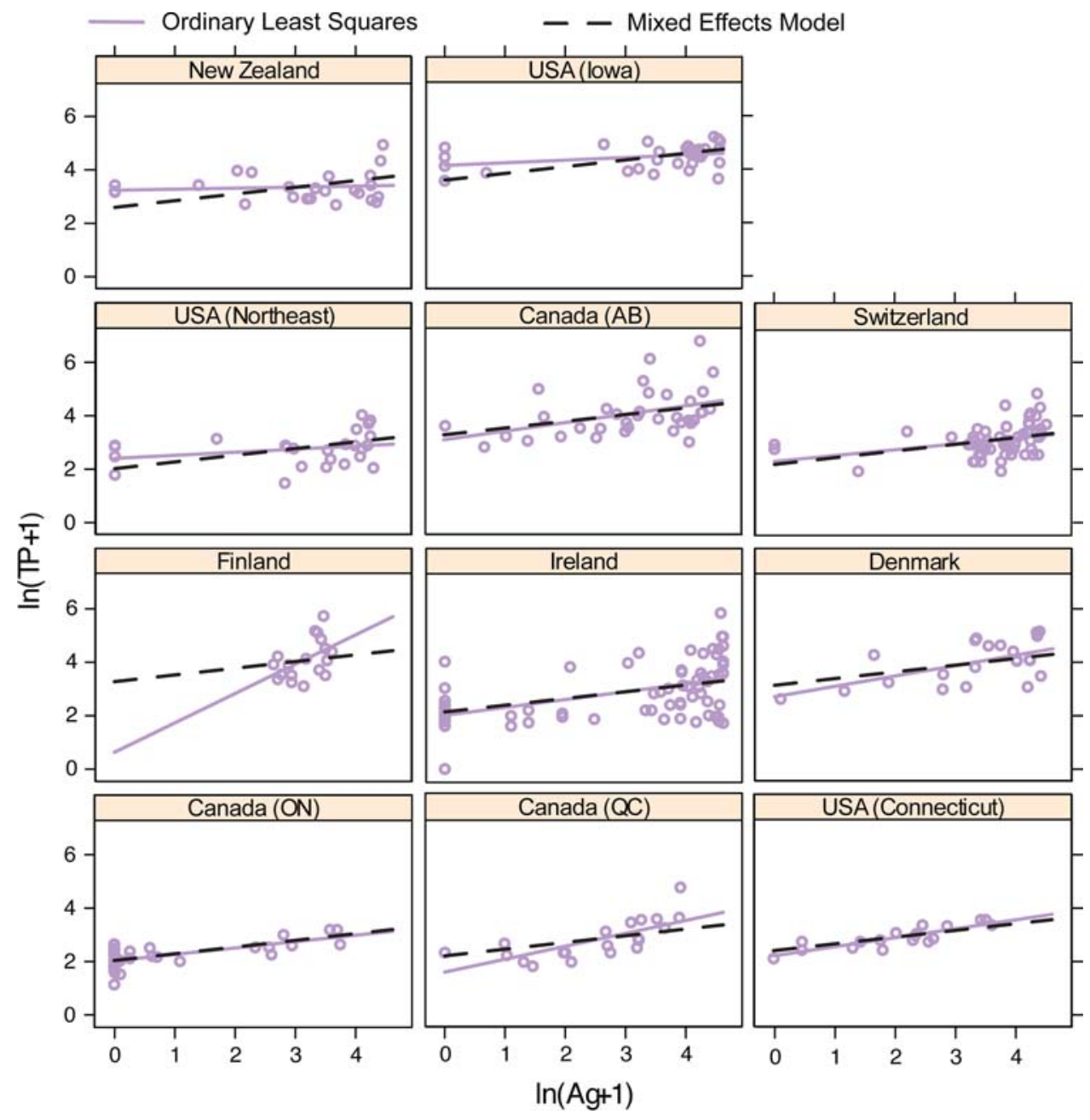

'shrink' the individual OLS estimates toward the common population estimate, providing robustness to individual outlying behavior (Pinheiro and Bates 2004). The shrinkage toward the common term is particularly noticeable in the Finnish dataset (Figure 2; Ekholm and Mitikka 2006).

As the \% Agr slope coefficients showed minimal variation across studies, incorporating a flexible \% Agr slope term into our mixed-effect model did not result in any sizeable reduction in the residual variance (Table 2). Therefore, model 9 did not perform significantly better than model 8 $\left(\chi^{2}=1.29 ; P=0.524\right)$. An ANCOVA of the TP-\% Agr relationship using study as a categorical variable, however, demonstrated that at least one slope differed significantly from others $(P=0.031)$.

\section{Mixed-Effects Models: Variability in the Correlative Relationship Between TP, $Z_{\text {mean }}$, and \% Agr}

Mean lake depth, a variable with the potential to influence a lake's response to agricultural activity,
Figure 2. Comparison of fitted lines for the TP versus $\%$ Agr relationships obtained when running separate OLS analyses for each study to the fitted lines obtained when running a mixed-effects model. 
was found to be a significant predictor of TP in our meta-analysis. By including both \% Agr and $Z_{\text {mean }}$ as common slope variables in our LMMs (equation $10)$, we noted a further reduction in the residual variance (Table 2 ). The common slope for $Z_{\text {mean }}$ was significant $\left(\beta_{2}=-0.4 ; P<0.001\right)$ and both the AIC and BIC decreased when this variable was included (Table 2 ).

We also found that the effect of lake depth on epilimnetic TP differed across regions as the rate of decrease in TP per unit increase in $Z_{\text {mean }}$ varied among studies, and thus model 11 with a flexible $Z_{\text {mean }}$ slope term was a significant improvement over model $10\left(\chi^{2}=8.03 ; P=0.018\right)$. This difference in $Z_{\text {mean }}$ slope coefficients is evident when comparing the slopes of the TP- $Z_{\text {mean }}$ relationship obtained from the study-specific OLS analyses to the common across-study LMM slope (Figure 3). The lower AIC for model 11 also suggests that this model is more robust than model 10. The BIC, however, would suggest the opposite scenario. We believe that the presence of a heterogeneous (that is, bimodal) distribution of the flexible $Z_{\text {mean }}$ slope coefficients may have resulted in a slight increase in the BIC of model 11 as this second information criterion penalizes more severely for violations of model assumptions (such as non-normality) than does the AIC. Ultimately, the AIC and BIC values for each model are still quite similar and thus the difference, albeit significant, is relatively minor.

\section{Discussion}

\section{Meta-Analyses and Mixed-Effect Models}

To date, numerous factors have been identified as drivers of eutrophication, both at the within-lake scale (that is, due to basin morphometry and trophic interactions) and at the catchment scale. At the catchment level, different sources of non-point agricultural loading (for example, row-cropping or animal husbandry; Arbuckle and Downing 2001),

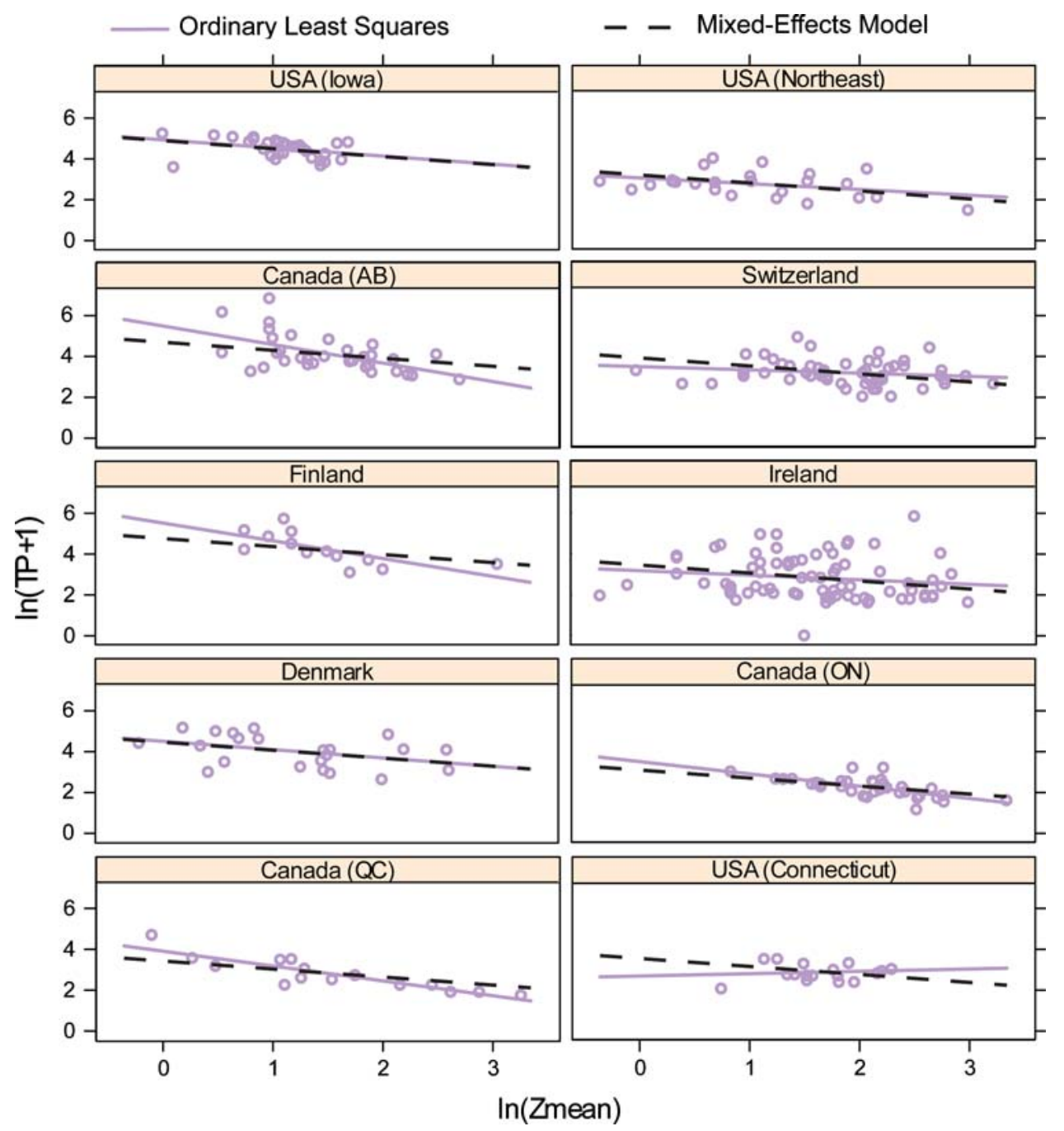

Figure 3. Comparison of fitted lines for the TP versus $Z_{\text {mean }}$ relationships obtained when running separate OLS analyses for each study to the fitted lines obtained when running mixed-effects models. 
catchment morphometry (Prairie and Kalff 1986; D'Arcy and Carignan 1997; Ekholm and others 2000), as well as differences in soil erosion, geomorphology, and hydrology (Reynolds and Davies 2001) can further affect limnetic nutrient concentrations. Despite these sources of environmental heterogeneity at broad, inter-regional spatial scales, we have shown through our meta-analysis that \% Agr explains $28 \%$ of the variation in TP, which is significant at the $\alpha=0.05$ level. This result underscores the earlier, more qualitative conclusion drawn by Carpenter and others (1998).

As we obtained negative values for the slope coefficients of the TP- $Z_{\text {mean }}$ relationships and positive values for the TP-\% Agr slope coefficients, we can conclude that at this inter-regional scale, shallow lakes in agriculturally dominated catchments are most likely to have higher TP concentrations. Effects of internal nutrient loading from the sediment to the overlaying water column are likely governing this heightened enrichment of shallow lakes (Scheffer 1998). Furthermore, given that lakes with smaller mean depths tend to be located in catchments with low-lying topography, longer contact times between runoff and agricultural land may lead to increased TP export from the land in shallow systems (Kalff 2001).

The LMMs provided additional information regarding the structure of the relationships in our meta-dataset. In particular, we detected significant variability in the intercept coefficients of the TP-\% Agr relationship, which confirms that across-study differences in background (that is, pre-impact) and internal loading exist. In contrast, our LMM detected no differences in slope coefficients, and thus the increase in epilimnetic TP per unit increase in agricultural cover was comparable across studies. The latter result was initially surprising as we expected a larger degree of variability in the effect of agriculture given regional differences in agricultural practices and geomorphologies. When we applied an ANCOVA to test for significant differences in slopes among studies, we found that at least one study slope differed significantly from others $(P<0.05)$. In our LMMs these differences were not observed. It is important to note, however, that the mixed-effects fitted values, which are based on both the common (fixed) and flexible (random) coefficient values, represent a compromise between the fit of the OLS regression coefficients, run separately for each study, and the mixed-effects common estimate associated with the entire dataset (across-study variable). As a result, the goal of mixed-effects modeling is to determine a general across-study slope and assign individual study variability relative to the common slope. Overall, we found merit in taking the extra step and applying an ANCOVA when no difference in slopes is detected with the LMM.

The observed among-study variability in the TP$Z_{\text {mean }}$ intercept and slope coefficients indicates that certain lake sets have higher average summer TP concentrations at given $Z_{\text {mean }}$ values with respect to other regional datasets, and that different rates of change in TP will be observed per unit increase in $Z_{\text {mean }}$. Given that external nutrient loading results in increased $\mathrm{P}$ accumulation rates to the sediment pool of lakes (Søndergaard and others 2002), and that total P retention by lake sediments is limited (Marsden 1989), we expect that lake sets under more severe and/or prolonged nutrient loading will be more eutrophic. A regression of the study slope coefficients from the TP- $Z_{\text {mean }}$ relationships against the median study TP values provides further support for this expectation; lake sets with steeper slopes tended to be more eutrophic $(r=0.51$, $P=0.06)$. We recognize, however, that acrossstudy variability in the TP- $Z_{\text {mean }}$ relationship may also result from additional factors, such as differences in the lake flushing rates and morphometry (Kalff 2001), climatic differences between systems that impact lake stratification and thus the oxidation status of sediments (Osgood 1988; Stefan and Fang 1994), and reduced iron availability (Gächter and Müller 2003).

\section{Implications for Ecosystem Management}

Given the predictions made by Tilman and others (2001) of an 18\% increase (above 1998 levels) in the amount of agricultural land worldwide by 2050, and our finding of a significant relationship between land use and water quality at an interregional scale, we can anticipate an increase in nutrient concentrations of lakes in the future. Furthermore, the observed across-study variation in our regression coefficients suggests that there will be regional differences in the response to expansions in agricultural land cover. According to our LMM (model 11), we would expect the Canadian Prairies and Northern Europe to be among the first of all regions studied to show signs of eutrophication (for example, cyanobacterial blooms, bottom-water anoxia) with future land use change as they are naturally more nutrient rich (that is, larger intercept coefficients).

Although we have advanced our understanding of the relationship between agriculture and water quality across large scales, there remains a need to conduct studies in tropical regions if we are to 
develop a robust estimate of the global impact of agriculture. More emphasis on the effect of agriculture in the tropics is essential because these regions currently have a large potential for land cultivation, but are likewise expected to rapidly lose soil fertility once the land is devoted to growing crops (Ramankutty and others 2002). As such, a better understanding of the TP-\% Agr relationship in these regions is needed. There is also a need to examine how specific land-management techniques influence the relationship between \% Agr and TP. For instance, several studies have shown that adopting a buffer zone around water bodies is one way of reducing nutrient export from land (Muscutt and others 1993; Sharpley and others 2000; Hickey and Doran 2004). Thus, when a sufficient number of such studies have accumulated, one could address how effective this technique is at an inter-regional scale. As our demand for both food and freshwater water is predicted to increase, and with the knowledge that agricultural activities have a significant effect on water quality across broad spatial scales, land management options such as buffer strips need to be more closely examined if we are to meet our future global demands.

\section{Conclusions}

We have shown with our application of meta-analytical techniques that the percent of agricultural land within a watershed and lake mean depth independently explain a significant proportion of the variation in limnetic TP concentration (explaining 28 and $16 \%$ of the variance, respectively). Given the broad geographic range represented by our datasets, it is fair to assume that the conversion of land to agriculture is an activity that will significantly increase summer TP concentrations in temperate lakes. With the use of linear mixedeffects modeling, we found that among-study variability arises from differences in pre-impact (background) lake trophic state and in the relationship between lake mean depth and lake TP. Therefore, some regions will show signs of lake eutrophication, such as cyanobacterial blooms and bottom-water anoxia, more rapidly than others. The identification of lakes that are the most susceptible to eutrophication from agricultural activity is critical for optimal management of competing ecosystem services (that is, provision of food and freshwater). Given the rise in food production that is expected to take place to meet the needs of an ever-growing human population, determining the global impact of agricultural development on freshwater ecosystems and identi- fying the most impacted regions is all the more pressing.

\section{ACKNOWLEDGEMENTS}

Funding for this research came from the Lakeland Industry and Community Association of Alberta (LICA) and McGill University. We appreciate the comments from Elena Bennett, Bronwyn Keatley, Daniel Selbie, Jesse Vermaire, and three anonymous reviewers on an earlier draft of this article. We also thank Brian Leung, Marco Rodriguez, and Russell Steele for advice on statistics. We are also grateful to the following authors for their enthusiasm and sharing of their data when need be; Burns CW, Chen G, Downing JA, Ekholm P, Galbraith LM, Müller B, Paterson AM, Prairie YT, and Vander Zanden JM.

\section{REFERENCES}

Arbuckle KE, Downing JA. 2001. The influence of watershed land use on lake N: $\mathrm{P}$ in a predominantly agricultural landscape. Limnol Oceanogr 46:970-5.

Bates DM. 2005. Fitting linear mixed models in R. R News 5:2730.

Bennett EM, Carpenter SR, Caraco NF. 2001. Human impact on erodable phosphorus and eutrophication: a global perspective. Bioscience 51:227-34.

Borsuk ME, Higdon D, Stow CA, Reckhow KH. 2001. A Bayesian hierarchical model to predict benthic oxygen demand from organic matter loading in estuaries and coastal zones. Ecol Model 143:165-81.

Carpenter SR, Caraco NF, Correll DL, Howarth RW, Sharpley AN, Smith VH. 1998. Nonpoint pollution of surface waters with phosphorus and nitrogen. Ecol Appl 8:559-68.

Chang LH, Hunsaker CT, Draves JD. 1992. Recent research on effects of climate change on water-resources. Water Resour Bull 28:273-86.

Chen G, Dalton C, Leira M, Taylor D. 2008. Diatom-based total phosphorus (TP) and $\mathrm{pH}$ transfer functions for the Irish Ecoregion. J Paleolimnol. doi:10.1007/s10933-007-9148-4.

D'Arcy P, Carignan R. 1997. Influence of catchment topography on water chemistry in southeastern Québec shield lakes. Can J Fish Aquat Sci 54:2215-27.

Dillon JP, Kirchner WB. 1975. Effects of geology and land-use on export of phosphorus from watersheds. Water Resour Res 9:135-48.

Dillon PJ, Rigler FH. 1974. The phosphorus-chlorophyll relationship in lakes. Limnol Oceanogr 19:767-73.

Downing JA, McCauley E. 1992. The nitrogen: phosphorus relationship in lakes. Limnol Oceanogr 37:936-45.

Ekholm P, Kallio K, Salo S, Pietiläinen OP, Rekolainen S, Laine Y, Joukola M. 2000. Relationship between catchment characteristics and nutrient concentrations in an agricultural river system. Water Res 34:3709-16.

Ekholm P, Mitikka S. 2006. Agricultural lakes in Finland: current water quality and trends. Environ Monit Assess 116:111-35. 
FAOSTAT. 2007. http://faostat.fao.org (last accessed Friday, July 27, 2007).

Gächter R, Müller B. 2003. Why the phosphorus retention of lakes does not necessarily depend on the oxygen supply to their sediment surface. Limnol Oceanogr 48:929-33.

Galbraith LM, Burns CW. 2007. Linking land-use, water body type and water quality in southern New Zealand. Landsc Ecol 22:231-41.

Hamm A. 1976. Nutrient load and balance of some subalpine lakes after sewage diversion. Verh Int Ver Theor Angew Limnol 20:975-84.

Hickey MB, Doran B. 2004. A review of the efficiency of buffer strips for the maintenance and enhancement of riparian ecosystems. Water Qual Res J Can 39:311-7.

ISI Web of Science. http://portal.isiknowledge.com/portal.cgi? DestApp=WOS\&Func=Frame (accessed Friday, July 27, 2007).

Johnson JB, Omland KS. 2004. Model selection in ecology and evolution. Trends Ecol Evol 19:101-8.

Kalff J. 2001. Limnology: inland water ecosystems. Upper Saddle River, NJ: Prentice-Hall, p 592.

Kass RE, Raftery AE. 1995. Bayes factors. J Am Stat Assoc 90:773-95.

Kronvang B, Aertebjerg G, Grant R, Kristensen P, Hovmand M, Kirkegaard J. 1993. Nationwide monitoring of nutrients and their ecological effects: state of the Danish aquatic environment. Ambio 22:176-87.

Kronvang B, Jeppesen E, Conley DJ, Søndergaard M, Larsen SE, Ovesen NB, Carstensen J. 2005. Nutrient pressures and ecological responses to nutrient loading reductions in Danish streams, lakes and coastal waters. J Hydrol 304:274-88.

Marsden MW. 1989. Lake restoration by reducing external phosphorus loading: the influence of sediment phosphorus release. Freshw Biol 21:139-62.

Millennium Ecosystem Assessment. 2005. Our human planet: summary for decision makers. Washington/Covelo/London: Island-Press. $109 \mathrm{pp}$.

Müller B, Lotter AF, Sturm M, Ammann A. 1998. Influence of catchment quality and altitude on the water sediment composition of 68 small lakes in Central Europe. Aquat Sci 60:316-37.

Muscutt AD, Harris GL, Bailey SW, Davies DB. 1993. Buffer zones to improve water quality: a review of their potential use in UK agriculture. Agric Ecosyst Environ 45:59-77.

Norvell WA, Frink CR, Hill DE. 1979. Phosphorus in Connecticut lakes predicted by land use. Proc Natl Acad Sci USA 76:5426-9.

Osgood RA. 1988. Lake mixis and internal phosphorus dynamics. Arch Hydrobiol 113:629-38.

Paterson AM, Dillon PJ, Hutchinson NJ, Futter MN, Clark BJ, Mills RB, Reid RA, Sheider WA. 2006. A review of the components, coefficients and technical assumptions of Ontario's lakeshore capacity model. Lake Reserv Manag 22:7-18.

Pinheiro JC, Bates DM. 2004. Mixed-effects models in S and SPLUS. Statistics and computing. New York, NY: Springer, p 528.

Prairie YT, Duarte CM, Kalff J. 1989. Unifying nutrient-chlorophyll relationships in lakes. Can J Fish Aquat Sci 46:1176-82.

Prairie YT, Kalff J. 1986. Effect of catchment size on phosphorus export. Water Resour Bull 22:465-70.

Pretty JN, Mason CF, Nedwell DB, Hine RE, Leaf S, Dils R. 2003. Environmental costs of freshwater eutrophication in England and Wales. Environ Sci Technol 37:201-8.
Ramankutty N, Foley JA, Norman J, McSweeney K. 2002. The global distribution of cultivable lands: current patterns and sensitivity to possible climate change. Glob Ecol Biogeogr 11:377-92.

R Development Core Team. 2007. R: A language and environment for statistical computing. R Foundation for Statistical Computing, Vienna, Austria. ISBN 3-900051-07-0, http:// www.R-project.org.

Reynolds CS, Davies PS. 2001. Sources and bioavailability of phosphorus fractions in freshwaters: a British perspective. Biol Rev 76:27-64.

Rosenberg MS, Adams DC, Gurevitch J. 2000. MetaWin: statistical software for meta-analysis Version 2. Sinauer Associates, Inc. Sunderland, MA.

Ryding SO. 1981. Reversibility of man induced eutrophication. Experiences of a lake recovery study in Sweden. Int Rev Gesamten Hydrobiol 66:449-503.

Scheffer M. 1998. Ecology of shallow lakes. Population and community biology series 22. Kluwer Academic Publishers. Principle editor: Usher MB. 357 pp.

Schindler DW. 1974. Eutrophication and recovery in experimental lakes: implications for lake management. Science 184:897-9.

Sharpley A, Foy B, Withers P. 2000. Practical and innovative measures for the control of agricultural phosphorus losses to water: an overview. J Environ Qual 29:1-9.

Smal H, Kornijów R, Ligeza S. 2005. The effect of catchment on water quality and eutrophication risk of five shallow lakes (Polesie region, Eastern Poland). Pol J Ecol 53:313-27.

Smith VH, Tilman GD, Nekola JC. 1999. Eutrophication: impacts of excess nutrient inputs on freshwater, marine, and terrestrial ecosystems. Environ Pollut 100:179-96.

Søndergaard M, Jensen JP, Jeppsen E, Møller PH. 2002. Seasonal dynamics in the concentrations and retention of phosphorus in shallow Danish lakes after reduced loading. Aquat Ecosyst Health Manage 5:19-29.

Soranno PA, Hubler SL, Carpenter SR, Lathrop RC. 1996. Phosphorus loads to surface waters: a simple model to account for spatial pattern of land use. Ecol Appl 6:865-78.

Stefan HG, Fang X. 1994. Dissolved oxygen model for regional lake analysis. Ecol Model 71:37-68.

Tilman D, Fargione J, Wolff B, D'Antonio C, Dobson A, Howarth R, Schindler D, Schlesinger WH, Simberloff D, Swackhamer D. 2001. Forecasting agriculturally driven global environment change. Science 292:281-4.

UNEP. 2007. Planning and management of lakes and reservoirs: an integrated approach to eutrophication. http://www.unep. or.jp/ietc/publications/techpublications/techpub-11/index.asp (last accessed: Friday, July 27, 2007).

Vander Zanden JM, Vadeboncoeur Y, Diebel MW, Jeppesen E. 2005. Primary consumer stable nitrogen isotopes as indicators of nutrient source. Environ Sci Technol 39:7509-15.

Vollenweider RA. 1968. Scientific fundamentals of the eutrophication of lakes and flowing waters, with particular reference to nitrogen and phosphorus as factors in eutrophication. Paris: OECD Technical Report. 159 pp.

Whittier TR, Larsen DP, Peterson SA, Kincaid TM. 2002. A comparison of impoundments and natural drainage lakes in the Northeast USA. Hydrobiologia 470:157-71. 